. W. 


\section{Aspectos sociodemográficos y laborales de las inmigraciones regionales en Honduras}

DAVID FIGUEROA*

RESUMEN. Los convenios y declaraciones que se han establecido en función de la temática migratoria, son determinados de alguna medida por las condiciones variantes en que los inmigrantes conviven y realizan sus actividades de tipo laboral en los países de destino. La informalidad y la precariedad, características de la mayoría de las actividades laborales que realizan los inmigrantes en Honduras, están relacionadas a la irregularidad en la documentación, la temporalidad del trabajo, la falta de empoderamiento del trabajador, los bajos salarios y las largas jornadas de trabajo. La violación de derechos humanos y laborales hacia los inmigrantes hace evidente la necesidad de estudiar la relación de estas situaciones. De lo anterior hay dos disertaciones que se contradicen entre el discurso y la realidad, hay un discurso que proclama la existencia de acuerdos y compromisos que obligan el cumplimiento de los derechos laborales; y por otra parte la realidad, mostrando las persistentes violaciones laborales de los inmigrantes. Hay que tener claro que la migración es un fenómeno en materia de derechos y que se relaciona linealmente con los nuevos desafíos del desarrollo en la región. En nuestro mundo globalizado, las mercancías principalmente de los países desarrollados no tienen fronteras y gozan de plena movilidad; mientras que los seres humanos de los países menos favorecidos cada vez enfrentan más restricciones para ejercer el derecho de emigrar. Aún así, es imposible imaginar un mundo en que las personas no se trasladen a través de las fronteras. No obstante, está sumamente comprobado que los migrantes contribuyen tanto a las sociedades de origen como a las de destino.

Palabras clave: migración, migración regional, movibilidad laboral.

ABSTRACT. The agreements and declarations that have been base set about migration are determined in some way for the variability of conditions that the immigrants live and make their Jobs in the destinations countries. The informality and precariousness are the most features of labor activities in Honduras are related to irregularities in the documentation, temporary jobs, lack of worker's empowerment, low salaries and log hours at job. The violation of human and labor rights to immigrants makes clear the need to study the relationship of these situations. From the last two dissertations that make a conflict between speech and reality, there is a speech that proclaims the existence of agreements and commitments that force the compliance of labor rights and reality, on the other hand, showing the persistent violations of immigrant's labor. It should be clear the migration is a phenomenon in human's rights and close related to the new challenges of development in the region. In our globalized world, the merchandise form developed countries have no borders and have full mobility, while the persons in the poorest countries face more restrictions on exercising the right to emigrate. It is still impossible to imagine a world in which the people do not move across the borders. However, it is highly proven that migrants make a contribution to both countries the one from origins and the destination country.

Keywords: migration, regional migration, labor mobility.

\section{Introducción}

La migración, situación humana integrante de la sociedad, se ha convertido en otro desafío que enfrenta la región. Dicho fenómeno muestra las contradicciones y el grado de desigualdad en cuanto a la carencia de factores de desarrollo en la mayoría de los pobladores que viven en la región, mostrando las múltiples dificultades de millones de personas para lograr obtener una vida digna en su lugar de origen.

Según lo manifestado por el Informe Mundial sobre Desarrollo Humano del año 2009, se expresa en tendencias generales que casi el $50 \%$ de todos los migrantes internacionales se desplaza al interior de su región de origen y más de un $40 \%$ a un país colindante. En nuestra zona geográfica, en la última década ha cobrado relevan-

Recibido: mayo 2013 / Aceptado y versión final: julio 2013.

* David Alexander Figueroa Toruño, Lic en Ciencias Sociales, Master en Demografía Social

Investigador asociado en Honduras del Instituto Centroamericano de Estudios Sociales y Desarrollo INCEDES con sede en Guatemala. 
cia la migración intrarregional con matices de obtención de empleo ya sea por períodos extensos o temporales. Personas procedentes de Nicaragua y El Salvador llegan a Honduras a realizar actividades relacionadas con el café; salvadoreños y hondureños llegan a Guatemala para trabajar en actividades relacionadas con la caña de azúcar. En fin la movilidad regional con fines laborales es un hecho y no simplemente con intenciones turísticas como se ha venido manejando.

Las personas migran en busca de mejores oportunidades, y ello lo lograran sólo accediendo a un empleo que le genere mejores ingresos. Los trabajos a los que accede un migrante principalmente los de situación irregular (mal llamado indocumentado o ilegal en muchos de nuestros países), son en su mayoría realizados en el sector de la construcción y la agricultura, caracterizados por ser trabajos con bajos salarios, largas jornadas de trabajo y con desventajas de beneficios en cuanto a las condiciones laborales y sociales. En cambio los migrantes regulares tienen mayores probabilidades de acceder a trabajos de actividades secundarias principalmente ubicadas en la industria y actividades terciarias como la prestación de servicios en distintas categorías.

Sin embargo, lo que es sorprendente es que de la condición del migrante irregular se fructifican las empresas dedicadas a la agricultura, manufactura, construcción, gastronomía, servicios hoteleros, domésticos y hasta sexuales. Las condiciones de estos trabajos en algunas situaciones tienen características denigrantes, complejas e inseguras, los salarios son bajos y los derechos de seguridad social son casi inexistentes.

Cierta responsabilidad de esta problemática expresada anteriormente, radica en los empleadores y en el Estado. En primera instancia los empleadores de cierta forma se benefician económicamente al reducir los derechos laborales y sociales de los inmigrantes y es por ello que realizan formas de contratación para atraer de alguna manera a esta población necesitada de trabajo. En segunda instancia el Estado a través de sus diversas secretarías sigue actuando de forma pasiva, al no controlar y sancionar a este tipo de empleadores.

Es esencial analizar desde una perspectiva crítica las dimensiones e interacciones sociales, económicas, culturales, políticas y demográficas de los flujos y los cambios migratorios en los distintos países de la región y en el caso particular que nos concierne: Honduras. Al escudriñar a fondo estos aspectos, se visibilizaran resultados con la intención de ejecutar acciones efectivas y no de figurillas que convierten a la migración en un derecho generador de oportunidades. Por tanto, hay que tomar en consideración las transformaciones en la dinámica demográfica y en la multivariabilidad de los procesos migratorios prevalecientes en los países de la región y que se han tornado más complejos y visibles en las últimas dos décadas. En este sentido, es necesario plantearse nuevos accionares teóricos, prácticos y metodológicos en la estimación y abordaje científico de la migración regional.

Una de las características de Honduras es la de ser un país de origen, de tránsito, de retorno y de destino de las migraciones. No obstante, éste artículo esta dirigido en visualizar a Honduras como país de destino de las migraciones regionales ${ }^{1}$ y en la caracterización sociodemográfica y laboral de estas personas que han llegado al país como los demás migrantes a nivel mundial, con un propósito dirigido a la búsqueda del bienestar individual que muchas veces se torna en familiar. En los últimos años, la tendencia en el país es hacia el decrecimiento de las inmigraciones, teniendo como causales importantes el deterioro económico y la reducción de posibilidades de ingreso y empleo; ahondando a la vez, situaciones de violencia extrema vividas cotidianamente en el territorio hondureño.

\section{Metodologia}

En Honduras aproximarse a la situación referida en cuanto a la población migrante es sumamente compleja, esto se debe en parte a la escasez de fuentes de datos 
constantes que traten este fenómeno y sus distintas dimensiones. A la vez existen pocas investigaciones con rigurosidad científica que involucren las distintas variables involucradas en este fenómeno social, que se ha diversificado en los últimos años. Por tanto debe existir una reflexión de las distintas organizaciones que apoyan la investigación, al brindar todo el apoyo necesario para la construcción de conocimiento ligado con las migraciones.

Para el desarrollo de éste artículo fue necesario en primer lugar el escudriñamiento documental y bibliográfico relacionado con las migraciones de destino y sus atractivos, esto con la finalidad de tener mayor afianzamiento conceptual y teórico del fenómeno planteado.

Se hizo preciso la realización de un mapeo social de organizaciones gubernamentales y de la sociedad civil involucradas en la temática de defensa de los derechos humanos de los migrantes para posteriormente ejecutar las distintas entrevistas a profundidad con personas especializadas de organizaciones como el Foro Nacional de las Migraciones en Honduras FONAMIH, Dirección General de Migración y Extranjería DGME, Secretaría del Interior y Población SEIP, Secretaría de Trabajo y Seguridad Social STSS, Pastoral de Movilidad Cristiana de Honduras PMCH, Centro de Atención al Migrante Retornado CAMR, Comisionado Nacional de Derechos Humanos CONADEH y la Comisión de Relaciones Exteriores del Congreso Nacional.

A la vez básicamente en el apartado 5, referido a los aspectos sociodemográficos de la inmigración regional en Honduras, se utilizó un enfoque metodológico basado en métodos y técnicas cuantitativas apoyado por los datos del Instituto Nacional de Estadísticas INE, Centro Latinoamericano y Caribeño de Demografía CELADE y de la Dirección General de Migración y Extranjería, que nos permiten elaborar estimaciones de las inmigración en Honduras en cuanto a tendencias poblacionales, dinámica y estructura poblacional, características económicas y sus distintos indicadores como la condición de actividad laboral, categoría ocupacional y ramas o sectores de actividad.

\section{Honduras y las inmigraciones dentro del contexto centroamericano, como parte de la globalización}

Centroamérica es una región geográficamente constituida por Guatemala, El Salvador, Belice, Honduras, Nicaragua, Costa Rica y Panamá, es una zona pequeña en tamaño de aproximadamente 524, 000 kilómetros cuadrados, equivalente a cerca de una cuarta parte del territorio mexicano y apenas la décima parte del estadounidense. En el año 2013 su población global se aproximaba a los 43 millones de habitantes.

Las condiciones de vida y de trabajo de la población centroamericana han sido consideradas como las de menor desarrollo en comparación a otras regiones de América Latina. Casi siempre los efectos de las crisis, ya habituales en los mercados internacionales, tienen sus efectos en la economía de Centroamérica, la cual se caracteriza por ser de monocultivo y generación de materias primas.

Los países centroamericanos comparten entre otras características comunes la pobreza, la marginación de las grandes mayorías, la vulnerabilidad hacia lo externo, la debilidad de los Estados y la poca organización de la sociedad. Esto ha dado como resultado rezagos, bloqueos y resistencia en un territorio de violencia que caracteriza su historia (Poitevin, 2002:25).

En cuanto a las migraciones estas encuentran entre sus determinantes primordiales las desigualdades en los niveles de desarrollo de las poblaciones, cuya notoriedad en el mundo globalizado aumenta las llamadas presiones migratorias. Es de hacer notar que las migraciones contemporáneas son más complejas que sus referenciales de períodos anteriores, en parte influenciada por los procesos de globalización sobre la dispersión territorial de las actividades productivas en diferentes regiones del mundo (Pellegrino, 2001: 15).

Este proceso de globalización, más la imposición del modelo neoliberal, según Camacho, 2007:2; han profundizado las desigualdades, tanto en el ámbito internacional como en el interior de los países, sobre todo en el nivel de 
ingresos y de oportunidades. Por tanto, Sassen, 1998:252 y 2003:40; explica que las migraciones son un componente de la economía globalizada, por lo que sostiene que los declives y transformaciones de la economía, no son una desviación o anomalía del sistema, sino elementos estructurales del mismo.

En relación a estas apreciaciones con nuestro entorno geográfico, Morales, 2008:1; manifiesta que "si un rasgo simboliza a Centroamérica en la globalización, éste sería el de las migraciones internacionales". Así, los países de la región manifestaron en las últimas décadas un comportamiento inconsistente en sus economías reflejándose en las condiciones de vida de las poblaciones. En nuestros países los volúmenes alcanzados en los flujos migratorios han sido considerables; sin embargo, hay que destacar las movilizaciones de personas que se están desplazando dentro de la región, en donde estos países se han convertido en emisores y receptores de migrantes.

En este sentido, es importante fundamentar procesos de reactivación económica a través de la generación de empleos y de ingresos, que serán esenciales para llevar a cabo una estrategia regional que fomente relaciones de trabajo de mayor modernidad, las cuales se requieren para garantizar la viabilidad social y política en la región (Lundahl; Pelupessy, 1989: 29). Como parte de lo anterior, es importante mencionar el planteamiento de Hernández Alcides, 1994:233, quien manifiesta que para que el mercado regional funcione y responda a las dinámicas de oferta de estos países, se requiere que la población centroamericana mejore sus condiciones de ingreso y que "no hay que esperar el milagro del derrame de la olla o del barril para que las cosas cambien".

En relación a Honduras, éste es un país vulnerable a las oscilaciones de los mercados internacionales, principalmente de materias primas, ya que este territorio es de vocación netamente agropecuaria, por tanto, se trata de un país de dimensiones reducidas hacia un desarrollo limitado y desencajado en los sectores secundarios económicos como la producción industrial y tecnológica. "La economía hondureña se ha caracterizado por la alta inestabilidad y la falta de competitividad, por lo que su desempeño ha estado por debajo de su potencial. Los limitados recursos disponibles no han sido dirigidos a los sectores más productivo (mayor retorno), lo que afecta el desenvolvimiento y la capacidad de crecimiento de la economía" (Flores, 2008: 2).

Las políticas estatales no han tenido mucho éxito en lograr los ajustes productivos necesarios, ni en amortiguar los efectos de las crisis. Además hay que agregar la ancestral dependencia externa la cual influye directamente en las estructuras del país, agregando a los grupos políticos y económicos dominantes internamente que no han perdido su capacidad de apropiarse de la mayor parte de los recursos generados. Los distintos gobiernos han creado posturas protectoras para los diferentes grupos de poder consagrando los monopolios y oligopolios a través de las exoneraciones, subsidios y privilegios especiales.

No se puede dejar de lado las dificultades que tiene el país en relación a la pobreza, ligada a la irregular distribución del ingreso y de los medios necesarios para obtenerlo, a la inversión insuficiente en capital humano, que redunda en baja productividad y bajos salarios especialmente cuando la pobreza aparece puntualizada en relación al ingreso percibido por los hogares (Cid, 1997: 56).

El Ingreso Nacional Bruto INB per cápita de Honduras, presenta bajos y lentos crecimientos que profundizan los altos índices de pobreza y desigualdad. Según estimaciones del Banco Mundial para el año 2011, éste era de 1,970 dólares, clasificando a Honduras como el tercer país de menor INB per cápita de América solamente superando a Nicaragua y Haití.

Los problemas de desempleo y subempleo en el país son evidentes, la preocupación es mayor al analizar el alto crecimiento de estas dos variables en los últimos años, mientras que no se observan políticas claras y estratégicas que reviertan esta situación. Según el Instituto Nacional de Estadística INE, para el año 2011 la población económicamente activa del país era de 3.369,919 personas y de éstas 1.854,033 se encuentran con problemas de empleo. Es decir por cada 10 hondureños y hondureñas que se encuentran en la población económicamente activa 
casi 6 presentan dificultades de empleo y que cada día la situación se complejiza aún más en éste aspecto.

Relacionando el contexto anterior con las inmigraciones de personas hacia Honduras, se puede mencionar que la mayoría de las movilidades poblacionales se desarrollan debido a que los países de destino presentan algún tipo de atractivo para los inmigrantes, la atracción muchas veces está ligada a la obtención de mejores ingresos a través de una ocupación laboral. En este caso Honduras, donde no existe una diversificación y desarrollo de las distintas actividades económicas relacionado con la poca diversidad ocupacional, salarios reducidos, incumplimiento de legislaciones de protección al trabajador y el crecimiento de la violencia generalizada en los distintos puntos geográficos, vuelve al país poco atractivo como destino de las migraciones.

\subsection{Honduras como país de destino de las migra- ciones regionales}

La zona geográfica Mesoamericana donde se localiza Honduras presenta componentes de recepción de personas cuyas pruebas datan de aproximadamente 10,000 años. Posteriormente Honduras se destaca como país receptor de españoles en el periodo de la conquista y colonia entre el siglo XVI y principios del siglo XIX, estos migrantes llegaron no con el propósito de radicarse definitivamente en el país, sin embargo, fueron claves en el proceso de mestizaje, dado no solamente en Honduras sino también en toda América Latina (Figueroa, 2011: 294).

En el año de 1797, llegan a Honduras procedentes de la isla caribeña de San Vicente un grupo de afrodescendientes llamados Garífunas, que también son conocidos con el nombre de Garínagus, los cuales en la actualidad conforman una población importante y destacada que se ha extendido principalmente en la costa atlántica del país.

En el siglo XIX la inmigración fue un punto presente en la agenda de los gobiernos. En 1825, José Cecilio del
Valle $^{2}$ manifestaba que era necesario atraer extranjeros útiles para la agricultura por tanto había que dar a conocer las bondades del país y brindar toda la protección necesaria para su establecimiento, auxiliándolos en los costos de viaje y primeros cultivos. La política migratoria de 1866, decretada por el presidente José María Medina, concedía a todos los inmigrantes con intención de domiciliarse en el país los mismos derechos que gozaban los nativos. Luego, el gobierno reformista instaurado en 1876, realizó intentos para atraer población extranjera principalmente vinculada con actividades industriales.

Otro período histórico de Honduras como país receptor se dio a finales del siglo XIX y principios del siglo XX, con personas atraídas del sudeste asiático, China e islas caribeñas por el incipiente desarrollo agrícola y comercial provocado principalmente con la implementación y auge del enclave bananero. Subsiguientemente en los años 30 de ese mismo siglo, se creó la Oficina de Inmigración y Colonización a cargo del Ministerio de Gobernación, con el objeto de hacer llegar al país a expertos en agricultura y ganadería, para que enseñara a nuestros compatriotas la manera científica de trabajar esos ramos.

En el mismo siglo entre las décadas de los setenta y ochenta llegaron al país salvadoreños y nicaragüenses por situaciones de guerras civiles y dictaduras y en menor cantidad guatemaltecos, particularmente indígenas de las zonas fronterizas, escapando de la persecución y discriminación racial. ${ }^{3}$

Actualmente están sucediendo de forma más visible desplazamientos de tipo laboral dentro del territorio hondureño de personas provenientes de Nicaragua y El Salvador, para trabajar en actividades relacionadas con el café, tabaco y la caña de azúcar. Estas se caracterizan por ser actividades de temporada, en donde en ocasiones estas personas deciden si radicaran parcialmente o definitivamente en el país.

2. Conocido como el sabio Valle, redactó el acta de independencia de Centroamérica el 15 de septiembre de 1821.

3. Honduras recibió en las décadas del 70 y 80 del siglo XX, a 37,000 refugiados provenientes de Nicaragua, El Salvador y Guatemala, posteriormente gran parte retornan a sus países en la década de los 90 gracias a transformaciones políticas y sociales en sus países de origen. 


\subsection{Aspectos sociodemográficos de la inmigración} regional en Honduras

La inmigración en Honduras de personas de los países centroamericanos como El Salvador, Nicaragua y Guatemala presenta mayor representatividad si se compara con los inmigrantes provenientes de otros destinos geográficos. El censo de población y vivienda del año 1988 registró un total de 34,387 residentes extranjeros en Honduras de esta cantidad 25,932 personas eran nicaragüenses, salvadoreños y guatemaltecos; 15,149 (58\%), $7,733(29 \%)$ y 3,050 (12\%) respectivamente. Estas cifras son altas en comparación a otros períodos, debido a que la década de 1980 fue un período de agudización de problemas internos en esos países y Honduras era un espacio que brindaba cierto grado de seguridad.

\section{Gráfico 1. Honduras: inmigrantes nacidos en Centroamé-} rica y México, años seleccionados

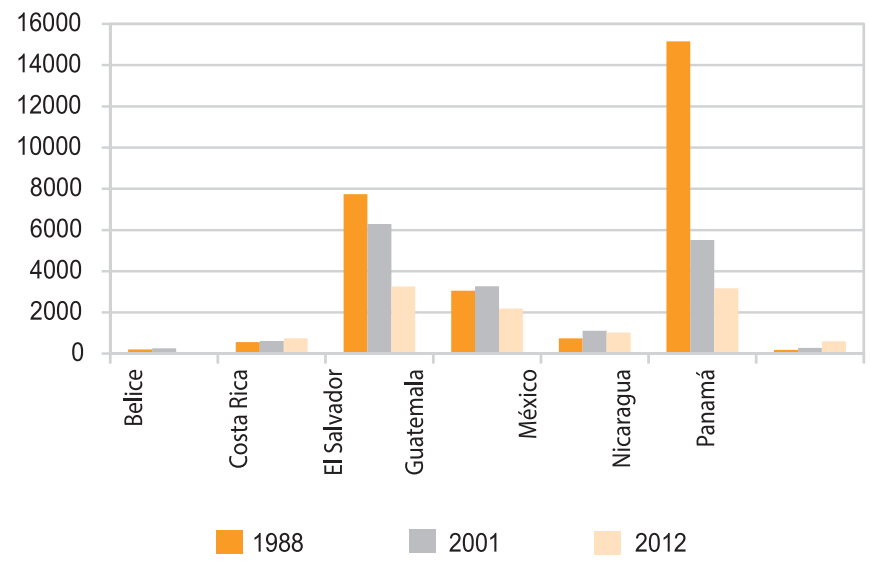

Fuente: Elaboración propia, Figueroa, David, 2013, con datos de los Censos de Población y Vivienda años 1988 y 2001, DGEC, INE; Secretaría de Población e Interior, Dirección General de Migración y Extranjería, 2012.

Posteriormente en la década de los 1990 se destaca la regularización de la situación política y social de estos tres países; a partir de entonces, la tendencia hasta nuestros días se ha dirigido hacia la disminución de la inmigración, posiblemente relacionado con el deterioro económico, político, jurídico y social del país, lo cual ha coadyuvado a que sea poco atractivo para personas de otras nacionalidades. Según la Secretaría del Interior y Población y la Dirección General de Migración y Extranjería los residentes centroamericanos incluyendo a los mexicanos para el año 2012 son 11,063 personas; de este total, más de las tres cuartas partes son de nacionalidad salvadoreña, nicaragüense y guatemalteca, quienes representan el $29.4 \%$, $28.7 \%$ y $19.8 \%$ respectivamente (Gráfico 1).

Se puede dilucidar que la representatividad de estas nacionalidades en el país se debe en parte a la relativa homogeneidad en aspectos culturales y económicos, a lo cual se agregan la cercanía geográfica por ser países colindantes y a la vez pertenecientes al acuerdo del CA-4. En este apartado no hay que descartar la presencia de la población originaria de México (9.2\%), para la cual en el año 2012, presenta mayores volúmenes en comparación a otros países centroamericanos como Costa Rica, Panamá y Belice.

Población por sexo y grupos de edad

La composición por sexo de la población inmigrante en Honduras provenientes de los demás países de la región difiere entre los de mayor presencia de población en el país, como El Salvador, Nicaragua, Guatemala y México; la población femenina es mayor en relación a la población masculina con un $52 \%$, observándose similares proporciones si se compara con la población nacional.

Cabe destacar que, entre estos países, es El Salvador el que presenta mayor feminización de su población en Honduras con un 55\%, al grado que la relación de masculinidad es 81 hombres por cada 100 mujeres. Los provenientes de Costa Rica, Panamá y Belice tienen una composición por sexo en la que la población masculina sobrepasa a la femenina en una relación de 53 a 47.

$\mathrm{Al}$ analizar la estructura poblacional por países, grupos de edad y sexo, el comportamiento de la dinámica poblacional es similar. La población inmigrante proveniente de la región presenta características en Honduras de una pirámide regresiva o de campana, observándose que las cohortes en la base son menores que la de los tramos intermedios representados por la población joven 
y adulta. Es de hacer la salvedad que en las cohortes hacia la cúspide existe un número importante de población adulta mayor inclusive similar a la de la base.

De seguir este comportamiento a futuro, es casi seguro el no reemplazo generacional de estas poblaciones inmigrantes debido a su crecimiento natural reducido. Este tipo de pirámides es frecuente en países receptores en donde ingresó y sigue ingresando población adulta en edades productivas que en algunos casos presentan edades un tanto avanzadas y que posteriormente en pocas décadas están cerca de convertirse en poblaciones adultas mayores.

Al agrupar la población en tres grandes conjuntos se puede afirmar que dos terceras partes de los inmigrantes regionales, es decir el 66\%, están comprendidas en el grupo entre los 15 y 59 años de edad, las personas de 60 años y más, es el segundo grupo de mayor participación con un 22\%. Las personas incluidas entre los 0 y 14 años de edad constituyen solamente el 12\% (Gráfico 2).

\section{Gráfico 2. Pirámide poblacional de inmigrantes regiona- les en Honduras}

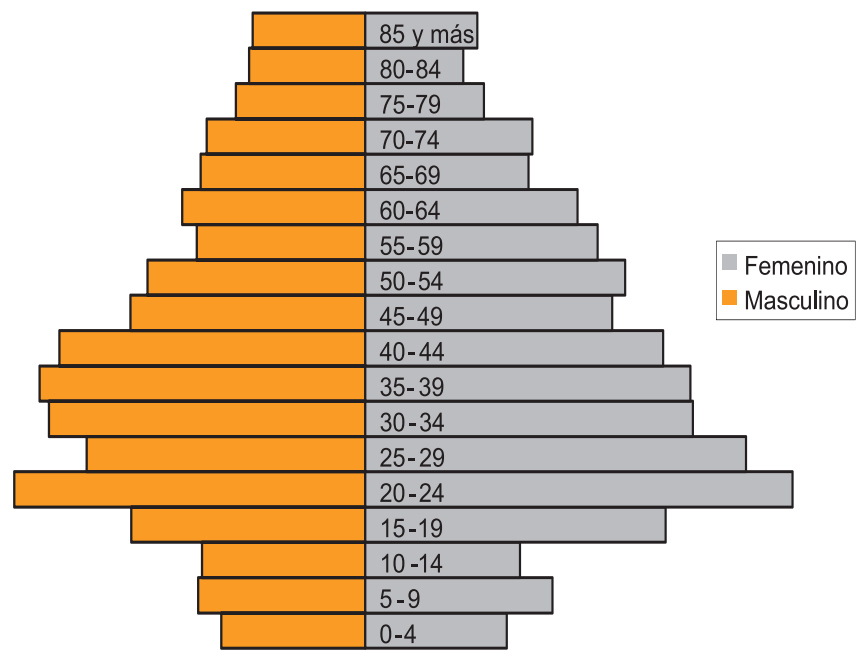

Fuente: Elaboración propia, Figueroa, David, 2013, con datos de IMILA, CELADE, 2012. Secretaría de Población e Interior, Dirección General de Migración y Extranjería, 2012.

Lo anteriormente expuesto confirma entre otras situaciones el carácter laboral de la inmigración por la concentración de grupos poblacionales productivos y a la vez la evidencia de procesos de feminización de la inmigración, pues ambos sexos se han movilizado al país en proporciones similares en aquellas edades favorables para incorporarse al mercado de trabajo.

Estado conyugal, zona de residencia y nivel de escolaridad

$\mathrm{Al}$ referirnos al aspecto estado conyugal, se incluye a todos los inmigrantes de la región en Honduras, se puede manifestar que en su mayoría, se encuentran casados (41\%) este dato tiene relación con la presencia o estabilidad en cuanto al tiempo de permanencia en el país y a la vez, con la acumulación en la estructura poblacional de personas de 20 a 39 años de edad; que según algunos estudios demográficos, son éstas las edades en la que los seres humanos se incorporan a procesos de nupcialidad.

Al realizar una distinción por países, el estado conyugal predominante con menos de la mitad de su población sigue siendo el casado; sin embargo, hay diferencias en la segunda posición donde para los nicaragüenses y salvadoreños es la unión libre, 26\% y 25\% respectivamente. Mientras tanto para las demás nacionalidades, el segundo estado conyugal sobresaliente con un poco menos de un cuarto de su población es el soltero.

Es de destacar que en la estructura poblacional de los inmigrantes regionales en Honduras hay un fuerte grupo que se encuentra en edades envejecidas y otro grupo que inevitablemente pronto llegará a formar parte de los adultos mayores. Estas son poblaciones que tienen varias décadas de residir en el país. Al vivir en Honduras en edades avanzadas hay fuertes probabilidades de que las defunciones ocurran en este país y por ello que un $8 \%$ de la población residente en este país se encuentre en estado de viudez, sobresaliendo los nacidos en El Salvador con un $13 \%$.

En cuanto a la zona de residencia de los inmigrantes regionales dos terceras partes viven en zonas urbanas. Al realizar la distinción por países se observa que los provenientes de Costa Rica, México y Panamá, casi en su totalidad viven en zonas urbanas $90 \%$, $87 \%$ y $86 \%$ respectivamente. Los países cuyos mayores porcentajes de su población residen en el área rural son los nacidos en El Salvador (43\%) y Guatemala (41\%). 
Los departamentos de Honduras de mayor atracción de inmigrantes de la región son Francisco Morazán y Cortés ambos departamentos suman 52\% de toda esta población. En ellos se encuentran las ciudades más importantes en número de habitantes, actividades económicas y decisiones políticas-administrativas, como son Tegucigalpa y San Pedro Sula, y ambas poseen un cuarto de la población total del país. No hay que menospreciar la presencia de inmigrantes de la región en los departamentos fronterizos como El Paraíso donde reside un $20 \%$ de la población total de origen nicaragüense y en el departamento de Copán con un 27\% del total de guatemaltecos.

Referente a los niveles de escolaridad de los inmigrantes de la región en Honduras, un fuerte porcentaje posee solamente nivel primario (34\%) y secundario (22\%). Al realizar la distinción por nacionalidades difiere en cuanto a los niveles de escolaridad principalmente el nivel superior; es aquí donde los panameños (40\%), costarricenses (32\%) y mexicanos (32\%), poseen un nivel de escolaridad universitario y a la vez son estos mismos países los que tienen mayores porcentajes de su población en el nivel de postgrado Costa Rica (5\%), México (4\%) y Panamá (3\%).

\subsection{Características sobre la actividad económica} de los inmigrantes

La condición de inactividad laboral en la mayoría de los inmigrantes de la región en Honduras, es mayor que la condición de actividad con una proporción de 54 inactivos por 46 activos, con la salvedad de los nicaragüenses que muestran una tasa de actividad de $55 \%$. Por sexo también los nicaragüenses superan a las otras nacionalidades, los hombres originarios de ese país presentan una tasa de actividad de $78 \%$ y las mujeres de $33 \%$. Los originarios de El Salvador son los que exhiben menores tasas de actividad con un $39.5 \%$, o sea que un 60.5 de esta población se encuentran inactivos donde se incluyen amas de casa, jubilados, pensionados, estudiantes, incapacitados para trabajar y personas que perciben dinero de sus rentas.
Con relación a la categoría ocupacional, en su mayoría se encuentran como empleados, destacando los originarios de Costa Rica y México con un 72\% y $69 \%$ respecto al total de su población residente en Honduras; sin embargo, es interesante analizar cómo las nacionalidades de mayor presencia en volúmenes de población como los provenientes de El Salvador (50\%), Guatemala (40\%) y Nicaragua (33\%) tienen un fuerte porcentaje de su población que son trabajadores independientes. Mientras tanto, los originarios de Costa Rica y México son los que presentan menores porcentajes como trabajadores independientes, con un 20\% y $22 \%$.

Los provenientes de México, Costa Rica y Nicaragua, $9 \%, 8 \%$, y $7 \%$ respectivamente se encuentran en la categoría ocupacional de empleador o patrono, o sea son personas que generan empleo a personas nativas de Honduras o posiblemente también a sus connacionales por medio de contactos o redes vinculantes con su nacionalidad; en este sentido habría que ahondar al respecto en futuras investigaciones.

En Honduras las actividades primarias juegan un papel fundamental dentro de la economía. Los inmigrantes de la región que residen en este país están insertos en un $22.83 \%$ en el sector de actividad donde se encuentran la agricultura, ganadería silvicultura y pesca. No obstante, debido al crecimiento de actividades comerciales, apertura de hoteles y restaurantes es donde están involucrados la mayoría de los inmigrantes regionales (24.23\%) (Cuadro. 1).

Es interesante mencionar que en Honduras mientras las actividades primarias se encuentran en un proceso de decrecimiento, siguen siendo importantes; sin embargo, las actividades secundarias y terciarias se acrecientan con el tiempo, por tanto son estas las que están reclutando porciones importantes de población nativa y extranjera.

A la vez se puede observar que al realizar una diferenciación entre países, se visibiliza que son los guatemaltecos y los salvadoreños quienes se encuentran insertos en mayor medida, casi un tercio de la población trabaja en actividades agrícolas, ganaderas, silvicultura y pesca. Los panameños, costarricenses y mexicanos tienen un fuerte 
Cuadro 1. Ramas o sectores de actividad en las que se encuentran involucrados los inmigrantes de la región en Honduras, por país de nacimiento

\begin{tabular}{|c|c|c|c|c|c|c|c|c|}
\hline Ramas de actividad & Guatemala & El Salvador & Nicaragua & Costa Rica & Panamá & Belice & México & $\begin{array}{l}\text { Total por } \\
\text { Rama }\end{array}$ \\
\hline Agricultura, ganadería, silv. y pesca & 29.0 & 33.08 & 17.08 & 5.56 & 7.39 & 16.13 & 2.23 & 22.83 \\
\hline Minas y canteras & 0 & 0.04 & 0.24 & 0.37 & 0 & 0 & 1.24 & 0.19 \\
\hline Industrias manufactura & 9.46 & 11.35 & 12.82 & 10.41 & 8.21 & 4.84 & 12.08 & 11.50 \\
\hline Electricidad, gas y agua & 0.39 & 0.21 & 0.38 & 0 & 0 & 0 & 0 & 0.28 \\
\hline Construcción & 5.08 & 4.47 & 4.88 & 3.73 & 4.93 & 9.68 & 5.42 & 4.81 \\
\hline Comercio, hoteles y restaurantes & 20.18 & 23.38 & 27.21 & 24.53 & 14.75 & 16.13 & 24.14 & 24.23 \\
\hline Transporte y comunicación & 2.50 & 2.40 & 4.13 & 2.97 & 3.24 & 9.68 & 3.45 & 3.25 \\
\hline Estable. financieros, bienes inmuebles & 4.77 & 2.83 & 5.85 & 11.53 & 11.48 & 8.06 & 9.85 & 5.29 \\
\hline $\begin{array}{l}\text { Servicios comunitarios, sociales y } \\
\text { personales }\end{array}$ & 22.36 & 15.49 & 20.18 & 32.34 & 38.52 & 22.58 & 32.25 & 20.45 \\
\hline Actividad no especificadas & 6.26 & 6.75 & 7.23 & 8.56 & 11.48 & 12.90 & 9.34 & 7.19 \\
\hline Total & 100.0 & 100.0 & 100.0 & 100.0 & 100.0 & 100.0 & 100.0 & 100.0 \\
\hline
\end{tabular}

Fuente: Elaboración propia, Figueroa, David, 2013, con datos del INE Censo de Población y Vivienda 2001; IMILA, CELADE, 2012.

grupo de su población ligado a actividades comunales, sociales y personales.

Respecto a lo anterior se puede manifestar el papel que juega los niveles de escolaridad y los grados de especialización de la población inmigrante de la región en Honduras, en la inserción a ciertos sectores de actividad. Personas con menores grados de escolaridad tienen mayores probabilidades de integrar actividades primarias como la agricultura, ganadería silvicultura y pesca; en tanto las personas con mayores niveles de escolaridad posiblemente se insertaran en actividades secundarias y terciarias. Es de hacer notar la poca inserción de los inmigrantes de la región en los sectores de actividad ligados con la minería, electricidad, construcción, transporte, finanzas y bienes inmuebles.

\subsection{Formas de ingreso a Honduras y su relación con el mercado laboral}

Honduras tiene fronteras terrestres con Guatemala, El Salvador y Nicaragua, con estos países colindan una serie de municipios donde se destaca la migración temporal. Según algunos investigadores, como Baumeister (2008:54), estas migraciones de temporada, son realizadas por hombres y en menor escala mujeres y cada uno de ellos haciendo actividades diferentes "los varones se van temporalmente (un mes) a los cortes de café; pocas mujeres emigran para trabajar como cocineras." En la segunda mitad de la primera década de este siglo se han dado inmigraciones en Honduras, tanto por occidente, para el cultivo y producción del tabaco y también en el oriente (Olancho), para dedicarse a labores ganaderas. También hay que destacar las actividades de corte de caña en los municipios orientales básicamente en el departamento de El Paraíso.

En Honduras, se tiene establecido cuales son los puntos de entrada y salida oficiales para personas y mercancías, siendo las delegaciones fronterizas, las aéreas y las marítimas, las que mantienen el control en el país; todas ellas en representación de la Dirección Nacional de Migración y Extranjería; por lo tanto toda persona que ingresa al país por los puntos no autorizados inmediatamente cae en una causal migratoria penalizada y esto se sanciona con la deportación.

Según la Dirección Ejecutiva de Ingresos DEI, Honduras cuenta con 17 aduanas, de estas 8 son terrestres, 2 aéreas y 8 son marítimas. Entre las aduanas terrestres se encuentran: El Poy y Agua Caliente (Departamento de Ocotepeque), El Amatillo (Departamento de Valle), La Fraternidad y Guasaule (Departamento de Cholute- 
ca), El Florido (Departamento de Copán), Las Manos (Departamento El Paraíso) y El Corinto (Departamento de Cortés). Entre las aduanas aéreas están: Toncontín (Departamento de Francisco Morazán) y La Mesa (Departamento de Cortés). Entre las aduanas marítimas se encuentran: Puerto Cortés (Departamento de Cortés), Roatán (Departamento de Islas de la Bahía), La Ceiba y Tela (Departamento de Atlántida), Trujillo (Departamento de Colón), Puerto Lempira (Departamento de Gracias a Dios), El Henecán y Amapala (Departamento de Valle).

Con todo el marco anterior, es importante mencionar el respeto de los derechos laborales de los inmigrantes, en donde son claves las distintas instituciones que trabajan en este tema ya sea de forma directa e indirectamente, entre ellas se encuentran los observatorios laborales, universidades, institutos de investigación y organizaciones de la sociedad civil y de derechos humanos (Cuadro 2).

En el caso de Honduras, el Observatorio de Mercado Laboral dirigido por la Secretaría del Trabajo, en su informe anual no toma en consideración la variable de migración en su apartado de mercado de trabajo; sin embargo, expresa que el mercado de trabajo en Honduras impone un estilo campesino, mayoritariamente por su actividad económica tradicional, con una productividad muy baja, con algún grado de modernidad en ciertas ramas. La fuerza laboral de Honduras recibe ingresos inferiores al salario mínimo, el cual en promedio por rama de actividad es de \$153.94 dólares por mes (STSS, 2009: 33).

Muchos de los trabajadores hondureños reciben un salario menor al estipulado en el salario mínimo, desde esta perspectiva se plantea la interrogante iqué pasa con los inmigrantes, principalmente los temporales y más aún los que se encuentran en situación migratoria irregular? ${ }^{4}$. Los inmigrantes según la ley constitucional de Honduras, pueden recibir menos salario que los trabajadores nacionales con un límite mínimo del 85\% respecto al 100\%. Ello significa que si un trabajador migrante trabaja en

\section{Cuadro 2. Municipios fronterizos de Honduras}

\begin{tabular}{|c|c|}
\hline \multicolumn{2}{|c|}{ Municipios fronterizos con Nicaragua } \\
\hline Departamento & Municipio \\
\hline Choluteca & $\begin{array}{l}\text { Duyure, San Marcos de Colón, Concepción de María, } \\
\text { El Triunfo }\end{array}$ \\
\hline Olancho & Catacamas, Dulce Nombre de Culmí \\
\hline El Paraíso & $\begin{array}{l}\text { Liure, Vado Ancho, San Antonio de Flores, Alauca, El } \\
\text { Paraíso, Danlí, Trojes }\end{array}$ \\
\hline Gracias a Dios & Wumpusirpi, Puerto Lempira, Ramón Villeda Morales \\
\hline \multicolumn{2}{|c|}{ Municipios fronterizos con el Salvador } \\
\hline Valle & Caridad, Aramecina, Alianza, Goascorán \\
\hline La Paz & $\begin{array}{l}\text { San Antonio del Norte, Opatoro, Mercedes de Oriente, } \\
\text { Santa Ana, Cabañas, Marcala, Yarula, Santa Elena }\end{array}$ \\
\hline Intibucá & San Antonio, Santa Lucia, Magdalena, Colomoncagua \\
\hline Lempira & $\begin{array}{l}\text { Piraera, Virginia, Mapulaca, La Virtud, Valladolid, San } \\
\text { Juan Guarita, Cololaca }\end{array}$ \\
\hline Ocotepeque & $\begin{array}{l}\text { Ocotepeque, Mercedes, Santa Fe (también con Gua- } \\
\text { temala) }\end{array}$ \\
\hline \multicolumn{2}{|c|}{ Municipios fronterizos con Guatemala } \\
\hline Ocotepeque & $\begin{array}{l}\text { Santa Fe (También con El Salvador), Concepción, Do- } \\
\text { lores, Merendón, San Jorge }\end{array}$ \\
\hline Copán & Copán Ruinas, El Paraíso, Florida \\
\hline Santa Bárbara & Nueva Frontera, Azacualpa, Quimistán \\
\hline Cortés & San Pedro Sula, Omoa \\
\hline
\end{tabular}

Fuente: Elaboración propia, Figueroa, David; 2013.

la industria manufacturera de una empresa, con más de 150 trabajadores, debería ganar \$ 353.38 dólares (según el Cuadro 3 de la tabla de salario mínimo del año 2012), al igual que un trabajador nacional, pero sólo por el hecho de ser inmigrante, ganaría \$ 300 dólares, al menos que el empleador le desee pagar igual que un trabajador nacional (Cuadro 3).

En relación a los inmigrantes irregulares incluyendo los temporales, existen acuerdos con el empleador en cuanto a los pagos, en donde en la mayoría de las ocasiones están ligados a situaciones establecidas por jornadas de trabajo llamadas también por jornal, o a la producción diaria según sea la actividad donde este inserto el inmigrante. Por tanto al inmigrante irregular y temporal ni siquiera se le paga lo estipulado en los salarios mínimos por actividad. Muchas veces estas personas son objeto

4. La población que emigra a los países de destino se le designa bajo dos nombres, una que es llamada migrante en situación regular (todo extranjero que se encuentra en un país con el permiso correspondiente de las autoridades competentes, lo hace gozar de la libre circulación) y la otra que es el migrante en situación la irregular (todo extranjero que se encuentra en un país sin el permiso correspondiente de las autoridades competentes y que está infringiendo las regulaciones establecidas en la ley). 


\section{Cuadro 3. Tabla del salario mínimo fijado para el 2012 (en dólares)}

\begin{tabular}{|c|c|c|c|c|}
\hline Rubro 0 actividad & $1-10$ & $11-50$ & $51-150$ & 151 y mas \\
\hline Explotación minas y canteras: & 320.70 & 330.32 & 345.28 & 348.56 \\
\hline Industria manufacturera & 314.58 & 334.38 & 350 & 353.38 \\
\hline Regionalizado & 176.28 & ------- & ------- & ------ \\
\hline Electricidad, Gas y Agua & 331 & 340.97 & 356.68 & 359.81 \\
\hline Construcción & 325.12 & 334.88 & 344.96 & 353.38 \\
\hline Transporte, Almacenamiento y Comunicaciones & 329.10 & 337.93 & 353.23 & 356.58 \\
\hline Establecimientos financieros, Bienes y Muebles & 334 & 344.02 & 390.14 & 363.02 \\
\hline Servicios Comunales, Sociales y Personales & 319.21 & 328.79 & 343.69 & 346.96 \\
\hline $\begin{array}{l}\text { Actividades de Investigación y Seguridad, } \\
\text { actividades de limpieza de edificios }\end{array}$ & 330.94 & 344.02 & 357.43 & 357.43 \\
\hline Actividades de hospitales & 319.21 & 328.79 & 341.62 & 341.62 \\
\hline Empresas acogidas a la Ley de Zonas libres & 236.30 & -------- & --------- & -------- \\
\hline
\end{tabular}

de violaciones laborales e inclusive ni el pago que se les ha ofrecido se convierte en efectivo, sólo por el simple hecho de pertenecer a otra nacionalidad o por encontrase en situación migratoria irregular.

\section{Conclusiones}

En base a todo lo anteriormente expuesto es importante destacar a manera de conclusiones, el respeto al acceso del trabajo ya que éste fortalece y promueve el desarrollo y la eficiencia de los derechos humanos de todas las personas en especial de los migrantes, y para remozarlo aún más es necesario la creación y el establecimiento de políticas migratorias, tanto en los países emisores, como en los de tránsito y de recepción. Hay que incentivar el interés de todos los países de la región para que promuevan iniciativas legislativas a favor de los migrantes, independientemente de su procedencia.

A la vez es importante la realización de investigaciones que defiendan los derechos humanos de los inmigrantes, es de vital importancia para visualizar los efectos de la discriminación laboral, étnica, sexual; amenazas físicas y psicológicas; engaños, trata de personas y otras. Es importante ver plasmadas en documentos de investigación con rigor científico, todas las situaciones que atraviesan los migrantes y así provocar procesos de acción de impacto ejecutados por las instituciones com- petentes. En Honduras hay encarecimiento de estudios rigurosos que tomen estas temáticas relacionadas con las migraciones regionales.

El proceso de migración intrarregional en el que Honduras es participe, ha traído lamentablemente consigo violaciones a los derechos de las personas que deciden venir al país a trabajar o simplemente transitar por él, siendo las personas en situación irregular las que se encuentran con mayores grados de vulnerabilidad. En el contexto de cada país, la población inmigrante principalmente la que se encuentra en condiciones irregulares, se halla en desventaja ante la población nacional. En este sentido se necesita realizar acciones conjuntas que busquen mejorar la atención a las necesidades de las personas trabajadoras migrantes.

La migración intrarregional, ésta siendo dirigida en Honduras hacia la participación de actividades laborales de temporada. Una parte de esta población de países vecinos que viene a Honduras lo hace con la intención de trabajar temporalmente en actividades relacionadas con el café, caña de azúcar y el tabaco. Estas personas llegan solas o acompañadas por algunos familiares o amigos para luego retornar a su lugar de origen. Sin embargo, también ocurre que algunas de estas poblaciones que llegan al país con toda su familia no retornan, más bien se instalan dejando sus lugares de origen de manera permanente. 
En Honduras todavía existen carencias y debilidades en cuanto a procesos o marcos jurídicos para la protección de la población inmigrante, de igual manera existe incumplimiento de convenios, convenciones y tratados internacionales referidos a la temática; sin embargo, hay que destacar el compromiso y trabajo de organizaciones de la sociedad civil e instituciones gubernamentales que trabajan con los derechos de los inmigrantes.

En todo este contexto es imprescindible la creación o el establecimiento de políticas migratorias referidas al mercado laboral qu podrían ser enmarcadas en parámetros bien definidos, para que tengan efectividad en el contexto de la realidad del país. Con estos parámetros se crearían políticas que podrían optimizar los beneficios de la migración laboral, con el apoyo de los acuerdos y convenciones sobre derechos humanos y migración.

\section{Bibliografía}

- Asamblea Nacional Constituyente (1982), "Constitución de la República de Honduras”, Tegucigalpa.

- BM, Banco Mundial (2011), "Ingreso Nacional Bruto Per Cápita Método Atlas", Washington, DC, USA.

- Baumeister E., Fernández, E., Acuña, G. (2008), "Estudios sobre las migraciones regionales de los nicaragüenses", Editorial de Ciencias Sociales, INCEDES, Guatemala.

- Camacho,Gloria, (2007), "Migraciones y políticas: una mirada desde el sur", The Chicago Council on Global Affairs Real Instituto Elcano, Atlantic Conference, Migration and migran integration in the atlantic región ceplaes.

- CELADE, Centro Latinoamericano y Caribeño de Demografía, (2012), IMILA, Información sobre Migración Internacional en América Latina.

- Cid, José Rafael del (1997), "Los pobres cuentan: pobreza y gobernabilidad en Honduras", FLACSO, San José, Costa Rica.

- DGEC, Dirección General de Estadística y Censos (1988), "Censo de población y vivienda”, Tegucigalpa, Honduras.
- Figueroa, David (2011), "Diagnóstico nacional de Honduras, Construcción de espacios y estrategias de dialogo y comunicación entorno a la problemática de migración y seguridad en Centroamérica y México", INCEDES-INEDIM, México, pp. 289-371.

- Flores, Pablo (2008), "Determinantes del crecimiento económico: una revisión de los hechos", Centro de Investigaciones y Propuestas Económicas y Sociales, Tegucigalpa, Honduras.

- Hernández, Alcides (1994), "La Integración de Centroamérica: desde la federación hasta nuestros días", Departamento Ecuménico de Investigaciones, San José, Costa Rica.

- INE, Instituto Nacional de Estadística (2012), "Problemas de empleo" Tegucigalpa, Honduras. http:// www.ine.gob.hn/drupal/node/174.

- INE, Instituto Nacional de Estadística (2001), "Censo de población y vivienda”, Tegucigalpa, Honduras.

- Lundahl Mats; Pelupessy Win (1989), "Crisis económica en Centroamérica y el Caribe”, Departamento Ecuménico de Investigaciones, San José, Costa Rica.

- Morales, Abelardo (2008), "Centroamérica: los territorios de la migración y la exclusión en el nuevo siglo", Foreign Affairs en español, abril-junio, pp 1-6.

- Pellegrino, Adela (2001), "iDrenaje o éxodo? Reflexiones sobre la migración calificada”, Universidad de la República, Facultad de Ciencias Sociales, Programa Población, Montevideo, Uruguay.

- Poitevin, Rene (2002), "Los desafíos de la democracia en Centroamérica”, FLACSO, Guatemala.

- PNUD, Programa de las Naciones Unidas para el Desarrollo (2009), "Superando barreras: movilidad y desarrollo humano", Informe sobre Desarrollo Humano, New York.

- Sassen, Saskia (1998), "Globalization \& its Discontents", Essays on the New Mobility of People \& Money. New Press. New York.

- Sassen, Saskia (2003), "Contrageografías de la globalización. Género y ciudadanía en los circuitos transfronterizos". Traficantes de sueños, Madrid.

- SGJH, Secretaría de Gobernación y Justicia de 
Honduras (2004), "Ley de Migración y Extranjería Honduras", Tegucigalpa.

- STSS, Secretaría de Trabajo y Seguridad Social, Dirección General de Empleo, Observatorio del Mercado Laboral (2009), "Informe del mercado de trabajo”. Tegucigalpa, Honduras.
- SEIP, Secretaría del Interior y Población (2012), "Datos Migraciones Internacionales, Sección de Deportados”, Dirección General de Migración y Extranjería, Tegucigalpa. 